\title{
PRINCÍPIOS DA PSICOLOGIA DA GESTALT APLICADOS \\ NA ANÁLISE DE COESÃO E COERÊNCIA TEXTUAIS \\ Siqueira, Kátia, Dr. \\ https://orcid.org/0000-0002-7955-6698
}

O presente texto pretende, numa abordagem cognitiva dos processos intra e intersubjetivos, tomando por base os princípios que a Psicologia da Gestalt propõe como organizadores da percepção, analisar as características de coesão e coerência do texto escrito, compreendendo que estas são fatores organizadores da percepção do sentido comunicado pelo texto. Uma vez que o objeto desta pesquisa é o texto, interessa, de início, que sejam analisados seus aspectos, visando ampliar sua compreensão na construção da abordagem cognitiva.

\section{ETIMOLOGIA E DEFINIÇÃO DE TEXTO}

Como se sabe, etimologia é o estudo da origem das palavras, enquanto definição indica aquilo a que se refere a palavra. O primeiro denota as raízes do léxico, enquanto, o segundo, mostra como é sua aplicação adequada. As palavras texto e tecido estão relacionadas etimologicamente por mesma raiz: o verbo latino texō (presente passivo texere), cujo particípio passado, textus (texto), tem uso também como substantivo (nominativo).

O Dicionário Etimológico (2008-2018) explica a origem das palavras tecido e texto. Quanto à palavra tecido, demonstra que sua etimologia remonta à língua latina:

A palavra tecido surgiu na língua portuguesa a partir do latim textus, derivado a partir texere, que significa "tecer" ou "entrelaçar algo com fios". Esta mesma raiz etimológica acabou dando origem ao termo texto. (...). Estima-se que os primeiros tecidos foram criados a aproximadamente 5 mil anos a.C, a partir do uso de algodão, linho e pele de animais. (...). 
Origem da palavra texto. Vem do latim texere (construir, tecer), cujo particípio passado textus também era usado como substantivo, e significava 'maneira de tecer', ou 'coisa tecida', e ainda mais tarde, 'estrutura'. Foi só lá pelo século 14 que a evolução semântica da palavra atingiu o sentido de "tecelagem ou estruturação de palavras", ou 'composição literária', e passou a ser usado em inglês, proveniente do francês antigo texte. (Dicionário Etimológico, 2008-2018).

Já a página especializada em etimologias, Definicón a (2018), diz sobre texto:

\section{Etimología de texto.}

Origen, historia o formación. Proviene de la palabra latina textus y hace referencia a un conjunto de enunciados que forman una unidad con significado. Textus es la sustantivación del verbo textere que significa entrelazar; un texto es un conjunto de enunciados entrelazados por el sentido.

\section{Definición de texto}

Concepto, significado o alcance. Tradicionalmente, se entiende por texto un conjunto de enunciados coherentes y estructurados que se transmiten de forma oral o escrita, no obstante, teóricos como Barthes, en una teoría más amplia del signo, propone que texto es todo aquello que puede ser leído, interpretado, que denote y connote (Definición a, 2018).

Curiosamente, Definición a (2018) segue abordando tecido a partir de seu significado dentro da área da histologia, ressaltando o agrupamento de células com mesma estrutura e função no organismo. 


\section{Etimología de tejido}

Origen, historia o formación. Ésta palabra es de origen latino, proviene del verbo tejere que significa unir, en este sentido, hace referencia precisamente a la agrupación de células que se unen para desempeñar ciertas funciones.

\section{Definición de tejido}

Concepto, significado o alcance

1. Textura de una tela en la cual se entrecruzan varias hebras o hilos. Etimología

2. Agregado de elementos anatómicos de la misma estructura y función (Definición a, 2018).

Em que pese certas imprecisões notadas nos excertos acima (mantidos com a estrutura original das citações), como a grafia do verbo original latino (texere ou textere) e de uma certa mistura nos conteúdos de etimologia, definição e conceito, as informações proporcionadas por eles são muito úteis ao propósito desta seção: o de estabelecer o estreito relacionamento entre as palavras tecido e texto.

A expressão "tecelagem ou estruturação de palavras", registrada acima, traduz o processo de composição semelhante do texto e do tecido. Ambos têm como resultante uma tessitura ou textura, ou ainda uma contextura ou urdidura. Urdir é tramar ou tecer, que leva ao resultado de urdimento, urdume, enredo ou trama. Também econtram-se em inglês e espanhol, respectivamente, os termos sinônimos texture, warp ou weave, e tesitura ou urdimbre. 
Mais adiante, verifica-se que a tessitura é o aspecto final da construção, tanto do texto, quanto do tecido, e que sua característica final assinalada, e que o define, é ser uma unidade com significado, entrelaçada por seus sentidos. Valiosa é a observação histológica de que tecido é um conjunto de células com mesma estrutura anatômica, desempenhando a mesma função. Fica, por analogia, aplicada a ideia de organicidade sistêmica tanto ao tecido, quanto ao texto, deixando lastro para expandir esta analogia com as características de harmonia e funcionalidade aos conceitos de coerência e coesão textual, a serem explorados mais adiante.

\section{CARACTERÍSTICAS, ESTRUTURAS E FUNÇÕES DO TEXTO}

O texto veicula mensagens que podem ser transmitidas de forma oral, escrita, verbais ou visuais. Ou, como já foi citado acima, todo signo que puder ser lido ou interpretado, por denotação ou conotação, a exemplo de discursos, filmes e artes visuais, nos quais são utilizados recursos linguísticos e extralinguísticos.

O presente estudo fixa-se apenas no texto escrito. Dentro deste modelo de texto, há algumas classificações que refinam a caracterização das estruturas e funções textuais. Dentre elas, uma à qual se deva atentar é a que estabelece diferença entre tipos e gêneros textuais, respectivamente agrupados por suas propriedades linguísticas e sociocomunicativas (Educação Globo, 2018). A mesma fonte cita as características principais de cada um: tipos e gêneros textuais, como a seguir.

Os tipos textuais variam de acordo com a forma na qual são construídas as frases, as relações lógicas constantes, os tempos verbais empregados e o vocabulário do qual se lança mão, por exemplo. São divididos mais comumente em: argumentativos, descritivos, narrativos, injuntivos e dissertativos. Não necessariamente precisam estar numa forma tipológica pura, pois, com frequência, em um mesmo texto, é possível constatar vários tipos textuais. 
Os gêneros textuais são produto da criatividade dentro dos contextos culturais, variando de acordo com estilo do produtor, o conteúdo que é tratado, a função a que se destinam e à forma de estruturação. Suas formas vão desde um romance ao inquérito policial, desde uma receita culinária a uma lista de compras, desde uma carta a um código de leis. Não há limites para os gêneros textuais.

Embora importante conhecer os grupos acima tratados, nesta seção não será focado um tipo ou gênero em particular. Importa aqui a perspectiva de que a boa tessitura do texto é fundamental para que o mesmo cumpra sua função de transmissor de ideias, adequadamente. Resgate-se, para isto, a ideia da seção anterior, de que a textura é o resultado do conjunto de enunciados arranjados sistemicamente de forma coerente e estruturada, responsáveis pela formação da unidade com significado. Em qualquer tipo ou gênero de textos escritos, é fundamental considerar que a organização de sua trama final é diretamente influente na qualidade da mensagem transmitida (sua boa forma) e, por consequência, percebida com o mínimo de viéses (ou biases) possível.

"Segundo Laila Vanetti, especialista em linguagem para a WEB, o termo texto deriva de textus, vinculado ao verbo latino texere (que, nos dicionários de latim, se enuncia texo, texis, texui, textum, o que equivale a teço, teces, teci, tecido). 0 sentido das palavra texto é o de tecer, enlaçar, entrelaçar."

"Daí estudiosos da teoria do texto falarem em tessitura e compararem o trabalho do produtor de texto ao de um tecelão que se vê às voltas emaranhado de fios e que utiliza toda sua habilidade para transformar esses fios em um tecido fino e de altíssima qualidade." 


\begin{abstract}
"Nesse sentido, o autor de um texto tece as idéias, enlaça as palavras e mobiliza toda sua capacidade criativa e organizadora para construir um enunciado que transmita, com clareza e objetividade, uma mensagem, e que se configure em um todo significativo com intenção de comunicar, colocando, assim, o emissor, em contato com o receptor." (Vaz, 2011, p.257).
\end{abstract}

Para tanto, o autor de um texto escrito, obrigatoriamente, deve conhecer o gênero textual que está a produzir, os tipos textuais que emprega ao desenvolvê-lo, e ainda saber quem é o público leitor para o qual se dirige. Bem como, deve atentar com zelo para a ordem que dá às ideias comunicadas, os artifícios estilísticos e estruturais dos quais lança mão, a sequencia lógica que emprega, a clareza e objetividade com que comunica. São condições a serem respeitadas para que sua mensagem chegue com o mínimo de distorção ao receptor, alcançando a melhor eficácia comunicativa.

Enquadrar o texto numa tipologia é compreender que cada texto corresponde a um esquema cognitivo composto por características organizadas por uma sintaxe particular, arquivadas na memória a longo prazo do escritor para servir como recurso nas tarefas comunicativas, nos sentidos de receção e produção linguística (input e output linguísticos) (Bonini, 1999). (Rodrigues, 2012, p.43).

Com isto, pode-se afirmar que o principal fator para que um texto seja eficiente é a mente que o produz. O tecelão de palavras é o agente comunicador que determina se a tessitura final terá boa forma ou não, se será facilmente percebida e se seus conteúdos, significados e sentidos serão apreendidos na mesma medida em que desejou transmiti-los, ou não. De todo, o autor do texto, através de suas habilidades e escolhas, é o principal responsável pela 
eficácia de seu produto final. Produto este que resulta de uma atividade mental cognitiva.

\section{O TEXTO COMO PRODUTO DE ATIVIDADE MENTAL COGNITIVA}

Flower e Hayes (1981), no artigo denominado de A cognitive process theory of writing, desenvolvem um modelo teórico para demonstrar "o processo de composição como uma série de decisões e escolhas" (Flower e Hayes, 2016, p.39). Esta é sua teoria de processos cognitivos na atividade mental da escrita, ou, segundo afirmam os Autores, de processos de pensamento enquanto se escreve (p.41). Neste sentido, explicitam os quatro pontos-chave de sua teoria da seguinte forma:

1. O processo de escrita é mais bem compreendido como um conjunto de processos mentais característicos que os escritores orquestram ou organizam durante o exercício da composição.

2. Esses processos têm uma organização hierárquica e altamente integrada, no qual um processo pode ser incorporado a qualquer outro.

3. O exercício da composição em si é um processo mental orientado por metas, guiado pela rede crescente de metas do próprio escritor.

4. Escritores criam suas próprias metas em duas chaves: ao gerar tanto metas de nível superior quanto submetas de suporte que materializam os objetivos em desenvolvimento (do escritor); e depois, às vezes, ao mudar as metas principais ou até estabelecer novas metas baseando-se no que foi apreendido durante a escrita (Flower e Hayes, 2016, p.41).

Seu grande avanço teórico constitui o fato de que deixaram de lado um modelo tradicional de fases lineares, para desenvolverem outro, baseado em processos e subprocessos com estruturas hierárquicas (o conjunto de processos mentais característicos). De acordo com o novo modelo, cada uma das atividades mentais pode ocorrer a qualquer tempo, sem o rigor 
linear da proposição tradicional. Admite simultaneidade de ocorrências e repetição de etapas (um processo pode ser incorporado a qualquer outro). Isto reflete melhor o processo natural da dinâmica mental na composição de textos.

Na psicologia e na linguística, um modo tradicional de olhar cuidadosamente para o processo é construir um modelo do que você vê. Um modelo é uma metáfora para um processo: uma maneira de descrever algo, como o processo de composição, que se recusa a ficar parado para um retrato. Como hipótese sobre um processo dinâmico, o modelo tenta descrever partes do sistema e como elas trabalham juntas. Modelar um processo começa como um problema de concepção (p.43).

Neste caso, adotaram a estratégia de usarem protocolos aplicados ao estudo de outros processos cognitivos, focados no escritor e com relatos em voz alta destes enquanto executavam a tarefa de redigir textos. A resultante da pesquisa é o esquema desenvolvido conforme adaptado na Fig.1, do modelo de Flower e Hayes (1981,p.47/2016,p.370) de processamento cognitivo da escrita.

A partir do construto teórico proposto pelos Autores citados, demonstra-se que a redação textual é a exteriorização, ou materialização de um processo mental cognitivo e, que seu produto, o texto - que é nosso objeto de pesquisa - é um legítimo produto de atividade psicológica. 
Fig.1 Modelo Cognitivo do Processo de Escrita, adaptado de Flower e Hayes, 2016, p.47

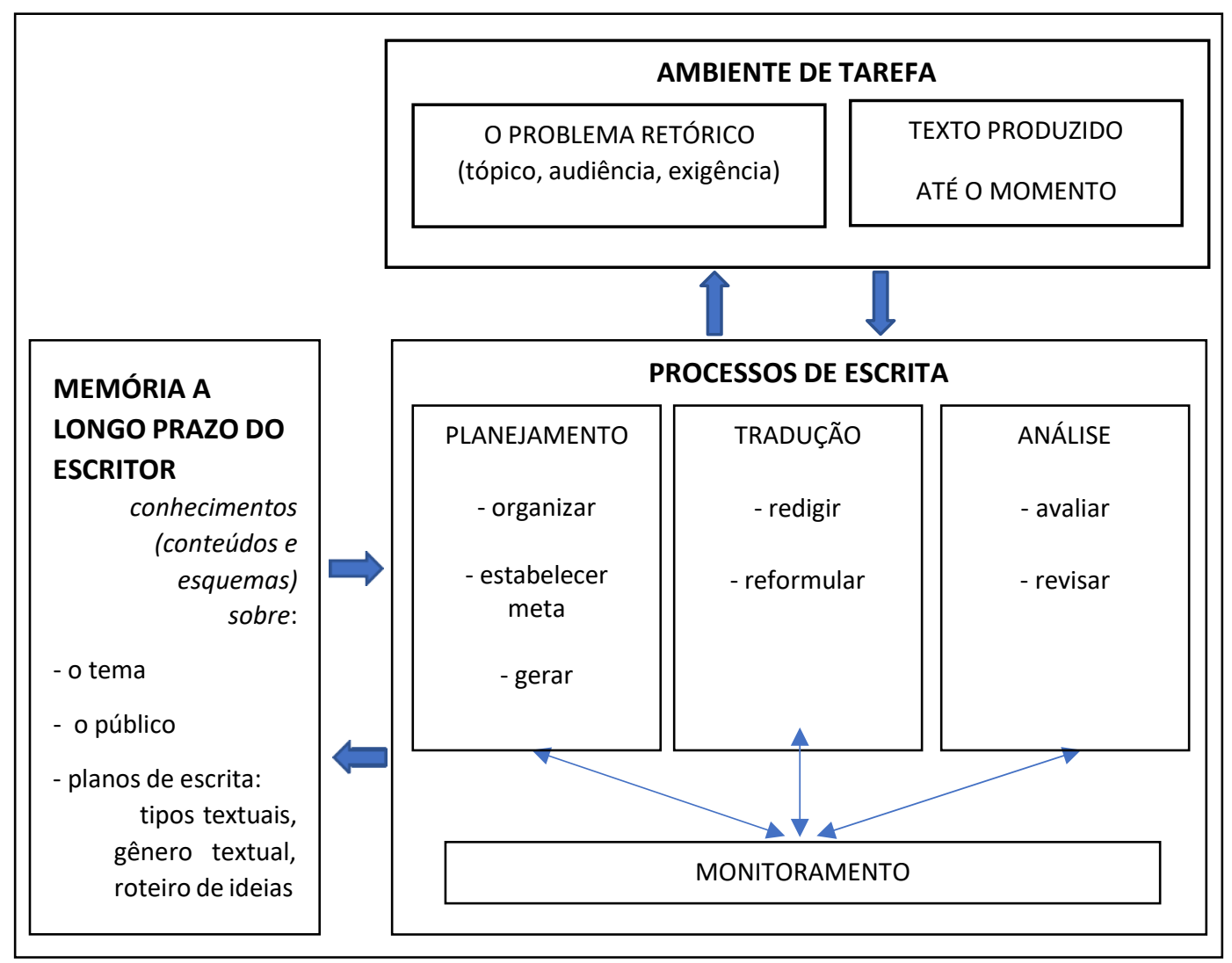

É possível abstrair do modelo proposto que os processos cognitivos dominantes, no elaborar um texto, são: planejamento, estruturação verbal e expressão das ideias (tradução), conferência do que já redigiu, avaliação, reavaliação e reedição, no sentido de reformular o já escrito, e fechamento da tarefa a partir da análise com resultados satisfatórios.

Planejamento implica combinar o conteúdo da memória aos esquemas de representação mentais (knowledge + schema), adequando ao gênero e tipos textuais adaptáveis, para estabelecer um roteiro de exposição de ideias, dispondo-as dentro de certo objetivo intencional. É atividade retomada ciclicamente ao longo da escrita, no sentido de adaptar e da reelaboração, em busca da forma final satisfatória.

Estratégias cognitivas do processamento de texto: escrever um texto acarreta administrar e organizar ideias, capacidades linguísticas, regras gramaticais, direcionamento de sentido e 
estruturação de significado, de modo tal que resulte em mensagem compreensível pelo leitor, da forma mais fidedigna possível à intenção do redator. E, curiosamente, é previsível que o próprio escritor seja leitor de seu texto, em momento posterior ao da produção. Neste caso, é um bom teste para saber se, ao ler, compreende o mesmo sentido e significado que pretendeu comunicar ao momento da confeç̧ão da textura.

\section{COESÃO E COERÊNCIA COMO FATORES ORGANIZADORES DE PERCEPÇÃO dO SIGNIFICADO E SENTIDO DO TEXTO ESCRITO}

O objetivo principal do processo de escrita: é (ou deve ser) formar uma unidade sistêmica, um todo coerente e coeso, composto por partes e subpartes que, por sua vez, também representem todos integrados e com sentido, de modo que o resultado final seja uma peça eficiente para a comunicação das ideias pretendidas. Cada ideia particular, desenvolvida ao longo do texto, deve ter seu início, desenvolvimento e conclusão particulares e, simultaneamente, participar coerentemente inserida no todo textual.

Bronckart (2010) defende que os elementos linguísticos que dão essa unidade ao texto são: a coerência (tanto temática como pragmática ou configuracional) que designa a propriedade de unicidade e inteligibilidade a que tendem os textos, e a coesão, que designa alguns dos mecanismos linguísticos utilizados para produzir o efeito de coerência (Rodrigues, 2012, p.25-26).

A coesão e a coerência textuais são parte da tessitura produzida pelo processo psicológico cognitivo da escrita de textos. Não se escreve para o vazio, mas para algum público leitor específico, que deverá aplicar suas habilidades cognitivas em compreender o texto. Mas, por melhores que sejam estas, o texto incoerente ou incoeso dificilmente será bem decodificado pelo receptor. 
A língua só funciona na interação e na interlocução de uma situação comunicativa e só fará sentido se houver coerência e coesão. Coerência e coesão estão correlacionadas no processo de produção e compreensão do texto, sendo que a coesão ajuda a estabelecer a coerência, mas não à garante. (...). A coerência está relacionada com a "boa formação" do texto, não gramaticalmente falando, mas em relação com a interlocução comunicativa que provoca a compreensão dos usuários. É vista também como a conexão entre os elementos do texto (Ludovico, 2014, p.1).

Quando se fala em boa formação do texto, é possível associar ao sinônimo boa forma da tessitura, e mais ainda, à uma boa forma da Gestalt que vem à luz, tomando em consideração suas figuras e fundo como todo integrado e levado à percepção através dos sentidos.

Prägnanz, ou pregnância, é esta característica da boa forma de uma contextura, fator básico ao qual se subordina toda nossa atividade perceptiva, sendo esta a tese defendida por Max Wertheimer em sua publicação Laws of organization in perceptual forms, de 1923 (Penna, 1993, p.115).

A tese central sustentada por WERTHEIMER é a de que toda a nossa atividade perceptiva se subordina a um fator básico, por ele designado de boa forma ou de pregnância (prägnanz), ao qual se associam fatores complementares tais como: proximidade, semelhança, movimento, boa continuação e destino comum. Estes últimos se constituem nas condições através das quais tem consumação a forma pregnante ou privilegiada. A propósito do fator boa forma ou de pregnância, podemos defini-lo como a tendência de que certa estrutura possui de revelar as características que a distinguem, de uma forma tão completa quanto as 
condições do momento o permitam e em termos de rigorosa economia (Penna, 1993, p.115).

De uma forma tão completa quanto as condições permitem, ou seja, tão boa forma quanto possa ser alcançada mediante a combinação dos elementos e o contexto nos quais se insere o objeto a ser trazido à percepção. No caso do texto, estes elementos são os signos linguísticos que formam o complexo de proposições semânticas, arranjados conforme as escolhas do escritor

Note-se que Wertheimer, apud Penna (1993), indica a boa forma como a urdidura principal de uma Gestalt, resultante da associação dos outros elementos, que, agrupados em um todo significante e com sentido, são tidos por fatores organizadores da percepção. No caso do texto, é possível atribuir à coesão e à coerência o papel de indicadores de proximidade, semelhança, movimento, boa continuação e destino comum das ideias que compõem a mensagem. A boa forma conduz ao fechamento da Gestalt, com um completamento gerador de sentido e significado satisfatórios.

A coerência, segundo Koch (1997), “diz respeito ao modo como os elementos subjacentes à superfície textual vêm a constituir, na mente dos interlocutores, uma configuração veiculadora de sentidos". A coesão, ainda segundo a autora, pode ser descrita como "o fenômeno que diz respeito ao modo como os elementos linguísticos presentes na superfície textual encontram-se interligados, por meio de recursos também linguísticos, formando sequências veiculadoras de sentido" (Bentes, 2003).

Assim, como num texto, o principal conteúdo veiculado são ideias, a percepção do sentido e 
do significado textual é construída a partir de ideias: os conceitos, as representações, as associações, tanto das memórias como dos esquemas, com conhecimentos já acumulados, a exemplo do proposto no modelo de Flower e Hayes descrito na seção anterior. Encontramos a informação de que

La percepción no está determinada simplemente por los patrones del estimulo sino que,(...) és mas bien una búsqueda dinámica de la mejor interpretación de los datos disponibles. Los datos disponibles iniciales son las caracteristicas del estimulo proximal A partir de allí, el sistema visual llevará a cabo una serie de operaciones de transformación, de síntesis y activaciones de conocimientos que tienen por objectivo transformar ese estímulo visual en un percepto que represente más fidedignamente al estímulo distal que desencadenó el proceso perceptivo (Redolar, , p.273).

O mesmo autor define percepção como uma atividade cognitiva do organismo provocada por estímulo, dado pela presença física de um objeto. Segue-se todo um desencadeamento de processamentos e informações que este estímulo provoca (Redolar, p.273). Quando, ocorre o contato visual com algumas linhas próximas tracejadas, dispostas como uma forma incompleta, o processo perceptivo (em milissegundos) tende a completá-las, dando a elas a forma final mais parecida possível com outro objeto já conhecido. Por exemplo:

n natn caiı do telhadn

Mas é possível compreender e as partes apagadas tendem a ser lidas como se estivessem completas, desde que haja preservação de um mínimo de traços recognoscíveis. Por exemplo: é legível que: "o gato caiu do telhado", ainda que o desenho das letras tenha sido cortado. 
De acordo com a Psicologia da Gestalt, de Kurt Koffka, Wolfgang Köhler e Max Wertheimer, do ínício do século XX, que trata muito profundamente da percepção da forma, quando olhamos ao redor, tendemos a perceber "uma ordem coerente, completa e contínua de figuras e fundos" (Sternberg, 2016, p.91).

Assim como a lermos o ambiente por "agrupamentos de objetos próximos (proximidade), ou de objetos parecidos (semelhança)" (p.91). Segue o Autor dizendo que, mesmo enxergando apenas uma parte dos objetos, tendemos a vê-los como todo (fechamento), e sua linhas descontínuas em continuidade, atentando mais para modelos que se mostrem em simetria do que os assimétricos. Enquanto alguns objetos se sobressaem, outros se misturam ao fundo difuso (figura-fundo), fazendo o direcionamento da atenção.

A Escola Gestáltica de Berlim (Berlin Gestalt Theory) propõe os princípios organizadores da percepção da forma, que organizam o percepto para resultar da forma mais estável e coerente possível (boa forma ou prägnanz). São eles: figura-fundo, proximidade, semelhança, continuidade, fechamento e simetria (p.92).

O que a Teoria da Gestalt da Escola de Berlim chama de teorias da percepção, também é conhecido como teoria do reconhecimento de padrões. Gross (2004, p.260) afirma que são termos quase sinônimos, sendo o reconhecimento facial um dos casos em que este estudo sobre padrões é aplicado.

El reconocimiento de patrones es el proceso mediante el cual se asigna significado a la entrada visual, mediante identificar los objetos en el campo visual (Eysenck, 1993). Aunque la capacidad para reconocer, identificar y categorizar objetos parece realizar-se sin esfuerzo, implica, de hecho, varios logros 
notablemente complejos. Aunque por lo general uno está consciente sólo de objetos estructurados y coherentes (p.259).

$\mathrm{Na}$ percepção e no reconhecimento de padrões ocorre identificar e categorizar automaticamente os estímulos percebidos. Necessariamente os estímulos precisam emitir uma figura que se destaque do fundo e, quanto melhor dispostos estejam os elementos de organização perceptual, maior será a capacidade de compreender o objeto-estímulo e de realizar sua "leitura", interpretando seu sentido e significado dados. Isto aplica-se aos objetos do ambiente em geral, incluindo-se neles o texto escrito.

1. La coherencia temática. Se refiere a la inteligibilidad de la organización y a la progresión de los distintos elementos de "contenido" que pueden expresarse en un texto, y este efecto se produce por la aplicación de tres tipos de mecanismos (Bronkart, 2010, p.1).

Os três tipos citados são mecanismos de conexão, que se dão através dos conectores, sintagmas nominais e sintagmas verbais. A coesão "designa algunos de los mecanismos lingüísticos que se utilizan para producir este efecto de coherencia", segundo Bronkart, 2010, p.2). Afirma também que coerência é uma propriedade global de significação de um texto, dada pela unidade e inteligibilidade presentes. Já a coesão é dada por mecanismos linguísticos usados para produzir o efeito de coerência (p.2).

Aplicando os princípios organizadores da percepção, dados pela Psicologia da Gestalt, ao texto (que é o produto de processos cognitivos do pensamento), observa-se que, para alcançar o objetivo de levar ao leitor a compreensão da mensagem intencionada pelo escritor, é imprescindível que a tessitura seja qualificada pela melhor "boa forma" possível 
(prägnanz). Quer dizer, que o texto seja estruturado da forma mais completa, equilibrada (estável e simétrica), coesa e coerente o possível, exigindo do leitor o mínimo de trabalho mental para decodificá-lo, reorganizá-lo e assimilar seu sentido e significado, características que atribuem a qualidade de eficácia comunicativa.

Quando as ideias e conceitos de um texto trazem coesão, formam sequências logicamente interligadas, que dão sentido de boa continuidade de raciocínio (coerência interna), movimentando-se harmonicamente em direção ao destino comum da transmissão do significado do texto como totalidade integrada e cognoscível.

A coerência textual demonstra proximidade semântica entre umas e outras ideias desenvolvidas na trama, revelando semelhança no seu papel de fundo integrado e subjacente à superfície textual formadora de coesão, dando suporte à veiculação dos sentidos em direção ao leitor.

\section{CONCLUSÃO}

Esta pesquisa teve o objetivo de demonstrar a aplicabilidade, ao texto escrito, dos princípios da Psicologia da Gestalt que regem a percepção da forma, trabalhando a hipótese de que coesão e coerência textuais comportam-se como fatores organizadores da percepção do sentido e significado da trama textual.

Explorou-se, neste caminho, a etimologia e definição de texto e tecido, abordaram-se as características, estruturas e funções textuais, demonstrou-se que o texto escrito é produto de atividade mental cognitiva, delineando seus principais processos e estratégias cognitivas, para finalmente trabalhar a relação entre coesão e coerência das ideias expressas no texto escrito, com os princípios organizadores da percepção propostos pela Psicologia da Gestalt. 
Foram usadas como bases teóricas a Linguística Textual, os estudos da percepção, tanto da Psicologia Cognitiva quanto da Neurociência Cognitiva e também recorreu-se ao entendimento da etimologia e do léxico para prover parâmetros linguísticos. A literatura especializada é extensa e foi necessário filtrar muito criteriosamente para atender ao limite de 12 páginas estabelecido para o presente trabalho.

Dentro da perspectiva estabelecida inicialmente, o resultado atendeu à expectativa de conseguir subsídios para formular a demonstração que confirma a hipótese de pesquisa, deixando o caminho preparado para que o tema seja ampliado por novas hipóteses em outras pesquisas, pois consciente da renovação contínua característica da Ciência. 


\section{REFERÊNCIAS}

Bents, Ana Christina (2001). Linguística Textual. In Mussalim, F.; e Bentes, A.C. (org.). Introdução à linguística 1: domínios e fronteiras (p.245-287). São Paulo: Corte.

Bonini, A. (1999). Reflexões em torno de um conceito psicolinguístico de tipo de texto. In D.E.L.T.A., (15), p. 301-318.

Bronckart, J.-P. (2010). Coherencia y cohesión. Leer para aprender - Leer en la era digital: Ministerio de Educación - Secretaria de Estado de Educación y Formación Profesional. Recuperado em 13 de março de 2018, de http://leer.es/documents/235507/242734/art prof ep eso coherenciaycohesion bronckart.pdf/1c2da2c2-1ba0-4728-b2e3-480ad5760d7f

Dicionário Etimológico: etimologia e origem das palavras. Portugal: Ed.7graus, 2008-2018. Recuperado de: https://www.dicionarioetimologico.com.br

Definición a: definición y etimología (2018). Colombia: E-Cultura Group. Recuperado de: https://definiciona.com/

Educação Globo (2018). Gêneros textuais. Recuperado de http://educacao.globo.com/portugues/assunto/estudo-do-texto/generostextuais.html

Flower, Linda; Hayes; e John R. A (dezembro,1981). Cognitive process theory of writing. College Composition and Communication, 32(4), p. 365-387. Recuperado de http://www.jstor.org/stable/356600?origin=JSTORpdf\&seq=1\#page scan tab contents

Uma teoria do processo cognitivo da escrita (2016). Revista revera: escritos de criação literária do Instituto Vera Cruz, (1).Recuperado de http://site.veracruz.edu.br/instituto/revera/index.php/revera/article/view/26/3

Ludovico, Francieli Motter (out/2014-mar/2015). Resenha sobre Texto e Coerência. Interletras, 20(3). Recuperado de http://www.interletras.com.br/ed anteriores/n20/resenhas/20.pdf

Penna, Antônio Gomes (1993). Percepção e realidade: introdução ao estudo da atividade perceptiva. Rio de Janeiro: Imago.

Ripoll, Diego Redolar. Neurociência cognitiva. Espanha: Panamericana, 2014.

Rodrigues, Marta Maria Roma (2012). Os subprocessos do processo de escrita. Portugal: Instituto Politécnico de Lisboa.

Sternberg, Robert J.; Sternberg, Karin. Psicologia cognitiva. São Paulo: Cengage Learning, 2016. 
Vaz, Conrado Adolpho (2011). Os 8 Ps do marketing digital: o seu guia de marketing digital. São Paulo: Novatec. 